\title{
Traduire
}

Revue française de la traduction

$230 \mid 2014$

À la croisée du texte et de l'image

\section{Événement : Lumières d'ailleurs. Rencontres de l'édition étrangère et de la traduction, Lyon 2014}

Andrea Genovese

\section{OpenEdition}

1 Journals

Édition électronique

URL : http://journals.openedition.org/traduire/641

DOI : $10.4000 /$ traduire.641

ISSN : 2272-9992

Éditeur

Société française des traducteurs

Édition imprimée

Date de publication : 15 juin 2014

Pagination : 126

ISSN : 0395-773X

\section{Référence électronique}

Andrea Genovese, «Événement : Lumières d'ailleurs. Rencontres de l'édition étrangère et de la

traduction, Lyon $2014 »$ "Traduire [En ligne], 230 | 2014, mis en ligne le 23 novembre 2015, consulté le 25 septembre 2020. URL : http://journals.openedition.org/traduire/641 ; DOI : https://doi.org/10.4000/ traduire. 641 


\title{
Événement : Lumières d'ailleurs. Rencontres de l'édition étrangère et de la traduction, Lyon 2014
}

\author{
Andrea Genovese
}

\section{NOTE DE L'ÉDITEUR}

Compte rendu extrait de Belvédère ${ }^{\circ}$ 27, janvier 2014, p.9.

1 Organisées par les étudiants du Master 2 Pro TLEC de la Faculté des langues de l'université Lyon 2, ces rencontres se sont tenues les 23-24-25 janvier 2014 dans le cadre suggestif du Musée des Moulages de Lyon. La conférence inaugurale a été confiée à Jean-Yves Masson qui a examiné du point de vue historique, littéraire, éditorial et disons, syndical, les aspects inhérents à la traduction, une véritable lectio magistralis. La première journée était axée sur différentes tables rondes privilégiant la traduction de et vers l'arabe, des questions d'altérité, l'é/moi et le tabou de l'autre, un concert de chant et un concert de oud.

Plus articulée, la deuxième journée, autour des langues et de l'interculturalité à Lyon 2, les causeries avec les étudiants du Master, un atelier de traduction littéraire avec voix de l'espace méditerranéen (espagnol, portugais, italien, arabe), et encore lectures de textes étrangers en bilingue avec dégustation de vins.

Riche aussi, la troisième journée, avec de nombreuses tables rondes (Le désir de l'Autre, Traduire: engendrer d'autres français, Plongée dans les littératures de la Méditerranée), et la remise du Prix de la Meilleure Traduction à Aurélie Bartolo (promotion TLEC 2011-2012). Nombreuses les personnalités de relief intervenues, entre autres Georges-Arthur Goldschmidt, Gisèle Sapiro, Vicente Cervera, Samia Kassab, Pascal Jourdana, Michel Volkovitch, Dominique Vittoz, Lise Belperron, Jean-Yves Loude, Jean-Claude Villegas. Cette première édition, par la richesse des échanges entre les professionnels et les futurs traducteurs, laisse bien augurer des prochaines, 
auxquelles une attentive réflexion sur l'expérience de cette année donnera sûrement plus d'éclat. 